\section{Medindo o processo de compressão da mortalidade no Brasil: uma apresentação dos indicadores}

\author{
Marcos Roberto Gonzaga* \\ Bernardo Lanza Queiroz ${ }^{* *}$ \\ Carla Jorge Machado***
}

A compressão da mortalidade é um processo por meio do qual ocorre um aumento na idade média à morte concomitantemente a uma redução na dispersão dos óbitos ao redor dessa idade (FRIES, 1980; WILMOTH; HORIUCHI, 1999). Esse processo, verificado na maioria dos países desenvolvidos, resulta de uma redução na dispersão da distribuição dos óbitos por idade, devido, basicamente, a mudanças estruturais e progressos no combate a doenças não transmissíveis. Outra forma de identificação do processo de compressão da mortalidade consiste em verificar que, na medida em que a distribuição da idade à morte torna-se menos variável, a curva de sobrevivência fica mais retangular em sua forma, processo denominado de retangularização da curva de sobrevivência (FRIES, 1980; WILMOTH; HORIUCHI, 1999). A Figura 1 ilustra os processos de compressão da mortalidade e retangularização da curva de sobrevivência, para a população total da Suécia em 1861 e 2006.

Uma revisão da literatura sobre o assunto indicou a existência de 27 indicadores voltados para mensuração desse fenômeno (Quadro 1), classificados de acordo com sua forma de construção. Por exemplo, os indicadores de compressão da mortalidade estão relacionados com uma maior concentração ou menor dispersão da distribuição dos óbitos por idade. Ao se considerar o número de sobreviventes à idade exata, estes indicadores podem ser classificados como de verticalização da curva de sobrevivência, pois, na medida em que as mortes se concentram num determinado intervalo etário, verifica-se uma maior inclinação negativa da função de sobrevivência naquele intervalo. Já os indicadores de retangularização da curva de sobrevivência estão relacionados com mudanças na topologia da função de sobrevivência. Com o avançar da retangu-

FIGURA 1

llustração dos processos de compressão da mortalidade e retangularização da curva de sobrevivência Suécia - 1861-2006
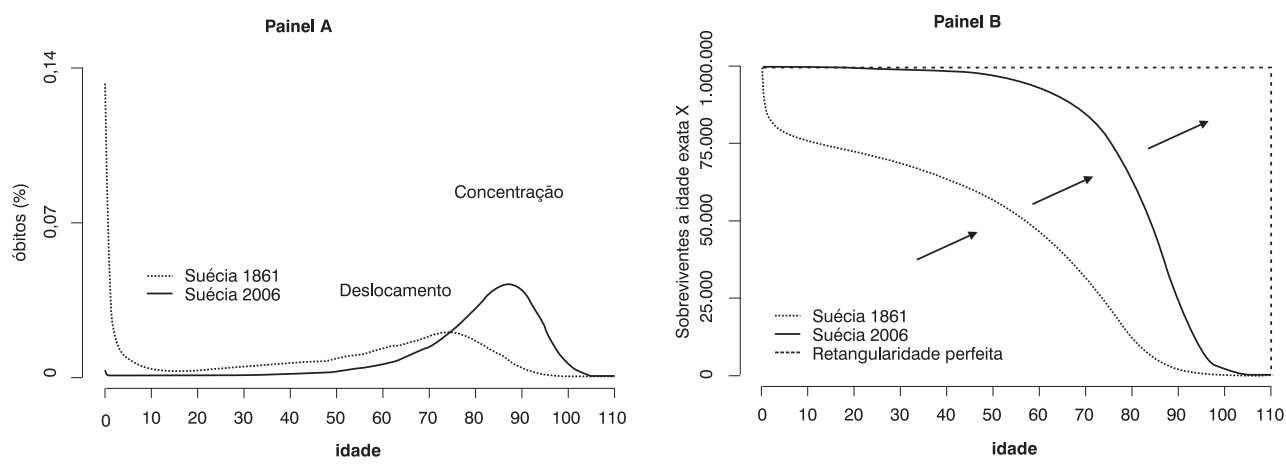

Fonte: Human Mortality Database (2007).

\footnotetext{
* Doutorando em Demografia. Departamento de Demografia da Faculdade de Ciências Econômicas da UFMG/Cedeplar.

** Professor adjunto do Departamento de Demografia da Faculdade de Ciências Econômicas da UFMG.

*** Professora adjunta do Departamento de Demografia da Faculdade de Ciências Econômicas da UFMG.
} 
larização, a função de sobrevivência apresenta uma forma mais retangular. $\mathrm{O}$ grau de horizontalização é classificado como tal porque corresponde a um aumento na probabilidade de sobrevivência, do nascimento a uma idade exata $x$. O resultado é uma tendência de "horizontalização" (função constante) da curva de sobrevivência da idade 0 a uma determinada idade exata $x$, em que, logo após, a função é rapidamente decrescente com a idade (ver Figura 1, Painel B). Os indicadores de longevidade central estão relacionados ao tempo médio de vida desde o nascimento, enquanto os de longevidade máxima medem o comprimento máximo do ciclo de vida de determinada coorte de nascimentos. Existem, ainda, alguns indicadores que não possuem uma classificação definida de acordo com a literatura.

Uma análise mais aprofundada desses indicadores permite identificar sua adequação de acordo com a qualidade e disponibilidade dos dados de determinada população. No geral, para aplicação desses

QUADRO 1

Classificação dos indicadores relacionados aos processos de compressão da mortalidade e retangularização da curva de sobrevivência

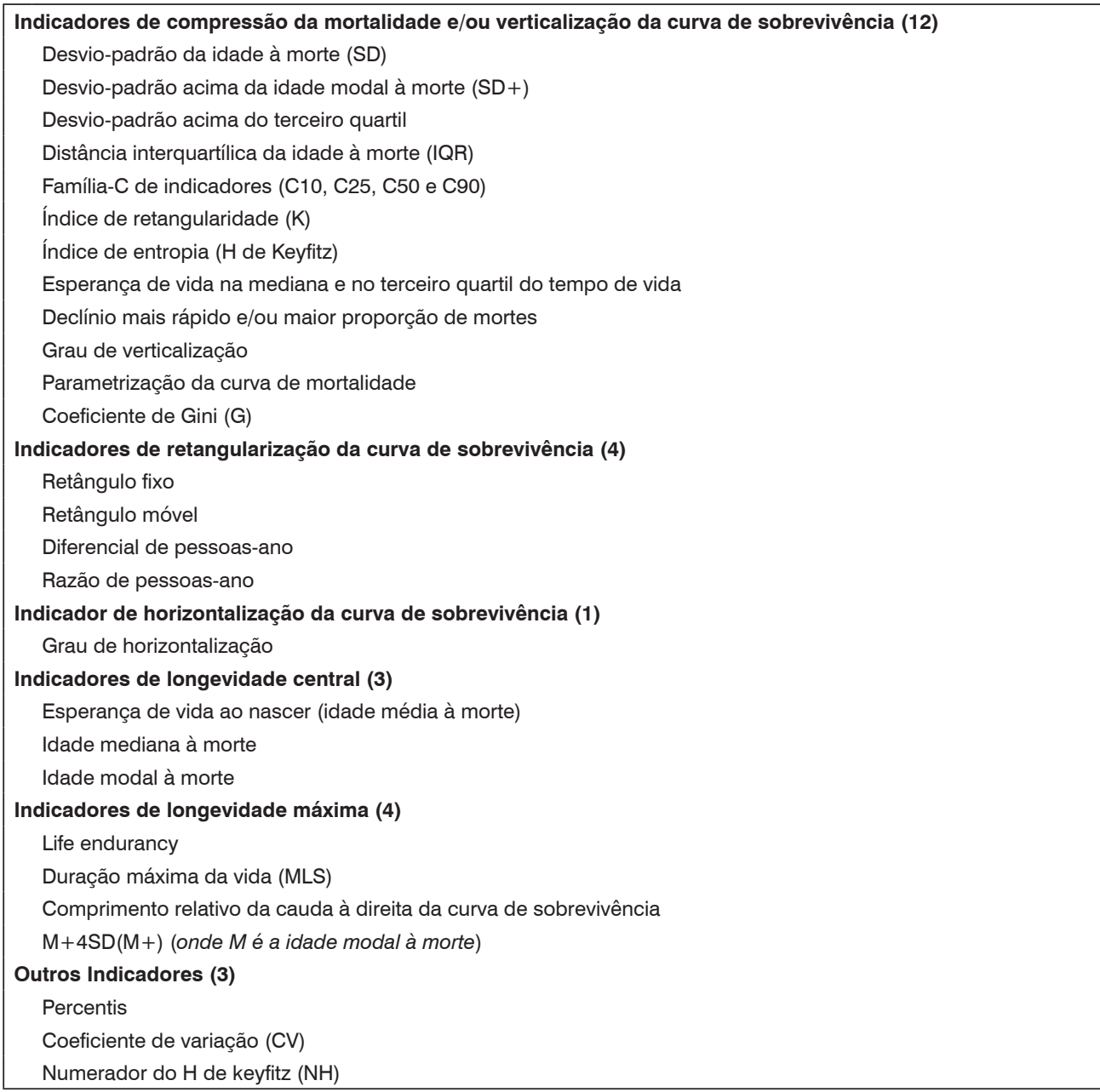

Fonte: Wilmtoh e Horiuchi (1999) e Cheung et al. (2005). 
indicadores, é necessário que se disponha de dados de boa qualidade sobre óbitos e população, especialmente nas idades mais avançadas, em que o processo se verifica. Essas informações possibilitam a construção de tábuas de vida que permitem estudar o comportamento do nível e da estrutura da mortalidade de determinada população, numa perspectiva tanto de coorte hipotética quanto de período (população estacionária). Basicamente, utilizam-se as informações do número de óbitos e sobreviventes à idade exata $x$, estimados na construção das tábuas de vida.

O propósito desta nota, oriunda da pesquisa acadêmica dos autores, é estimular pesquisas voltadas para construção de indicadores do processo de compressão da mortalidade no Brasil. Com o decréscimo das mortes prematuras (não relacionadas ao processo intrínseco de envelhecimento biológico) e reduções no período de incapacidade e enfermidade antes da morte, é possível pensar em uma aproximação das curvas de mortalidade e morbidade, fornecendo, assim, evidências empíricas de outro processo, o de compressão da morbidade (FRIES, 1980). Uma tendência de aproximação das curvas de mortalidade e morbidade pode fornecer insumos importantes, tanto para os formuladores de políticas públicas quanto para estudos relacionados à transição da mortalidade no Brasil.

Neste contexto, faz-se necessário apontar quais indicadores podem ser utilizados nos dias de hoje e quais os caminhos que devem ser seguidos para melhoria da qualidade dos dados, permitindo, assim, a aplicabilidade de outros indicadores na tentativa de identificar se, de fato, o processo de compressão-retangularização está ocorrendo.

\section{A adequação do indicador e a qualidade dos dados}

No que diz respeito à fonte de dados, uma situação ideal para a mensuração do processo de compressão-retangularização seria a disponibilização de informações do comportamento da mortalidade de várias coortes, desde o nascimento até a morte do último indivíduo. Entretanto, diante da impossibilidade de obtenção de tal informação, é necessário que se disponha de dados que permitam a construção de tábuas de vida que representem uma construção hipotética da situação ideal. Infelizmente, os dados existentes para o Brasil não possibilitam tal construção, devido à precariedade das informações de nonagenários e centenários, tanto de óbitos quanto de população.

Nesse contexto, entre os indicadores apresentados no Quadro 1, sugere-se a construção daqueles que não necessitem de dados em idades muito avançadas. Seguindo essa premissa, numa primeira tentativa de análise do processo para o Brasil, sugere-se desconsiderar a construção de indicadores de longevidade máxima. Além disso, com os dados disponíveis, dificilmente se conseguem boas estimativas de tábuas de vida truncadas em, por exemplo, 90 ou 100 anos e mais. Esta é uma limitação à construção de indicadores que exigem estimativas de curvas de sobrevivência ou de mortalidade bastante suavizadas nas últimas idades, como é o caso do desviopadrão acima da idade modal à morte $(\mathrm{SD}(\mathrm{M}+))$. Considerando a função de distribuição dos óbitos por idade numa tábua de mortalidade, essa medida baseia-se no fato de que, ao replicarmos, para o lado esquerdo, o lado direito da distribuição dos óbitos acima da idade modal à morte, o resultado seria uma curva descrevendo o que Lexis (1878) denomina "comportamento normal da vida".

A construção de indicadores do processo de compressão-retangularização considerados adequados para aplicação no Brasil merece cuidado, principalmente se a presença de erros de declaração de idade, tanto nos dados de óbitos quanto de população, for elevada. Nesse caso, estudos voltados para avaliação da qualidade dos dados de censo e registro civil nas idades avançadas são cada vez mais urgentes no Brasil. Do contrário, as pesquisas voltadas para avaliar os impactos da transição da mortalidade e, conseqüentemente, subsidiar políticas públicas não ultrapassarão a barreira da falta de dados de boa qualidade. 


\section{Referências bibliográficas}

CHEUNG, S.L.K.; ROBINE, J.M.; TU, E.J.C.; CASELLI, G. Three dimensions of the survival curve: horizontalization, verticalization, and logevity extension. Demography, v. 42, n. 2, p 243-258, May 2005.

FRIES, J.F. Aging, natural death, and the compression of mortality. The New England Journal of Medicine, v. 303, n. 3, p. 130135, Jul. 1980.

LEXIS, W. Sur la durée normale de la vie humanie et sur la théorie de la stabilité des rapports statistiques [on the normal human lifespan and on the theory of the stability of the statistical ratios]. Annales de Démographie Internationale, Paris, v. 2, n.5, p. 447-460, 1878.

WILMOTH, J.R.; HORIUCHI, S. E. Rectangularization revisited: variability of age at death within human populations. Demography, v. 36 , n. 4, p. 475-495, Nov. 1999.

Recebido para publicação em 13/01/2008. Aceito para publicação em 14/11/2008. 